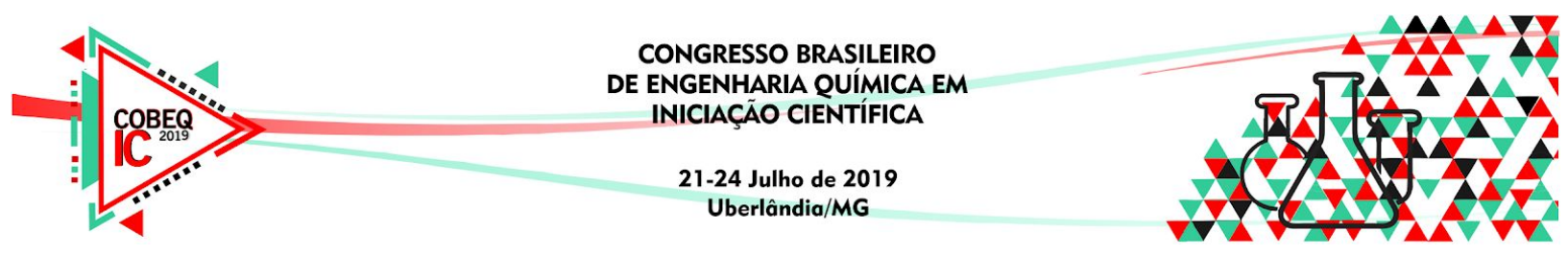

\title{
IMOBILIZAÇÃO DE PROTEÍNAS EM MEMBRANAS OBTIDAS POR IMPRESSÃO 3D COMO FERRAMENTA PARA CONSTRUÇÃO DE BIOCHIPS
}

\author{
R. PAULA ${ }^{1}$, W. KOPP, C. SARGO, E. J. NASSAR ${ }^{2}$, J. V. L. SILVA ${ }^{2}$, H. S. BARUD ${ }^{3}$ e R. \\ L. C GIORDANO ${ }^{1}$. \\ ${ }^{1}$ Universidade Federal de São Carlos, Departamento de Engenharia Química \\ ${ }^{2}$ Universidade de Franca \\ ${ }^{3}$ Universidade de Araraquara, Laboratório de Biopolimeros e Biomateriais \\ E-mail para contato: depaula016@gmail.com
}

Como parte de um ramo da ciência altamente inovador, os biochips são ferramentas analíticas compactas que tem ampla aplicação em diversas áreas como no descobrimento de novas drogas e na triagem de pacientes. Nesse sentido, os biochips de proteína exercem um importante papel já que a maioria das funções do organismo humano são realizadas por essas biomoléculas. Uma outra tecnologia também crescente é a Manufatura Aditiva, que permite a criação de geometrias complexas por meio da impressão 3D. Unindo esses dois universos, este trabalho teve como objetivo realizar a imobilização de uma proteína ( $\beta$-xilosidase) em membranas de poliamida obtidas por Manufatura Aditiva, a fim de obter um material que futuramente pode servir como ferramenta para construção de biochips custo efetivos e totalmente customizáveis. A imobilização da enzima ocorreu de maneira efetiva, onde a melhor condição foi obtida quando a membrana passou por um pré-tratamento com $75 \mathrm{uL}$ do organosilano aminopropiltrimetoxisilano (APTES) e posteriormente foi ativada com 1,25\% de glutaraldeído. Neste caso, a atividade enzimática observada na membrana foi de 2,203 $\mu \mathrm{mol} * \mathrm{~min} / \mathrm{g}$ e houve mudança de coloração da membrana devido a hidrólise do substrato, indicando a possibilidade de utilizar essa estratégia para identificação visual da atividade de biomoléculas.

\section{INTRODUÇÃO}

Os biochips são dispositivos compactos que permitem a análise de centenas ou milhares de eventos de via genômica e proteômica simultâneamente. Atualmente, estes dispositivos possuem grande potencial de aplicação nas áreas farmacêutica, biomédica, de meio ambiente e de biodefesa (LI et al, 2008). Uma vez que grande parte das funções do organismo são executadas por proteínas, o estudo e desenvolvimento dos biochips de proteína representam um grande avanço, permitindo identificar funções protéicas específicas, diversas doenças ou o descobrimento de novas drogas (LI et al, 2008). Contudo, existem ainda grandes desafios no 


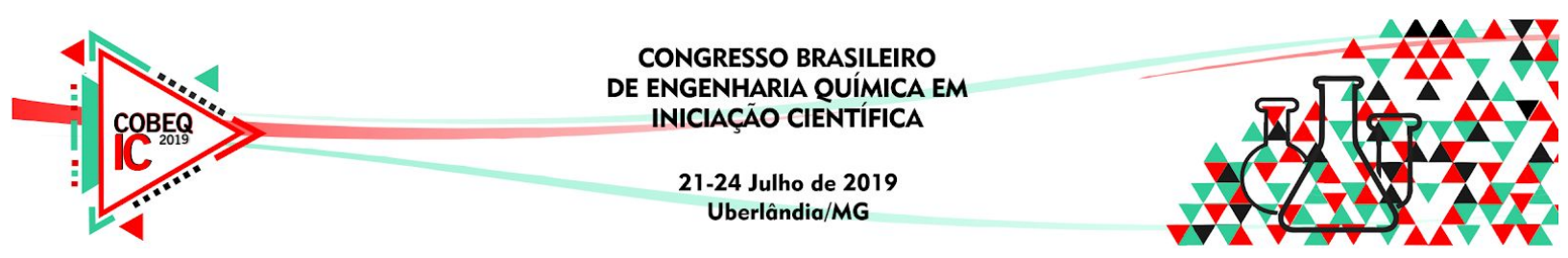

desenvolvimento dos biochips de proteína, pois estes compostos não se anexam facilmente em superfícies sólidas. Assim, um dos passos mais importantes para implementação dessa tecnologia, é estabelecer uma imobilização efetiva entre a biomolécula e o material (LI et al, 2008).

A imobilização de proteínas permite confinar a mesma em um suporte para futura utilização, restringindo seus movimentos. Tal confinamento é realizado por meio de adsorção, ligação química ou encapsulação (BECARO, 2008). Na construção dos biochips de proteína a imobilização por ligação covalente é a mais promissora, pois estabelece a mais forte ligação entre a proteína e a superfície do material (LI et al, 2008). Nesse sentido, grande atenção é dada aos suportes utilizados na imobilização de proteínas, principalmente no que se refere a modificação da superfície destes suportes. Tais modificações podem ser químicas, físicas e morfológicas além de possibilitarem uma melhora de estabilidade operacional. A inserção de grupos funcionais é um exemplo de modificação da química de superfície do material (CARVALHO et al, 2015). Vale ressaltar que essas modificações são necessárias pois a maioria dos materiais desenvolvidos não podem ser usados diretamente, e os exemplos mais comuns são aqueles em que ocorre um tratamento do material com organossilanos, como o aminopropiltrimetoxisilano (APTES) (LI et al, 2008).

Atualmente a Manufatura Aditiva (MA) tem sido investigada por diversos pesquisadores, pois permite a obtenção de peças de diversos tamanhos, formas e complexidades, gerando assim um grande leque de aplicações (SOUZA et al., 2018). Através da MA, é possível a obtenção de membranas constituídas de poliamida. A técnica baseia-se na construção por camadas de peças tridimensionais complexas utilizando processos automatizados, a partir de um modelo digital gerado em programas computacionais (CAD Computer Aided Design) (SOUZA et al, 2018. SOUZA M., 2016). Poliamida se constituí de segmentos de polietileno $\left(\mathrm{CH}_{2}\right)$ separados por monômeros de amida (NH-CO), formando um polímero capaz de realizar ligações de hidrogênio com outros compostos (SOUZA E., 2017).

Sendo os biochips parte de uma tecnologia que atualmente possui grande potencial na área de diagnósticos, triagem de pacientes, estudos toxicológicos e no desenvolvimento de novas drogas e devido ao leque de possibilidades geradas através da impressão 3D, este trabalho tem como objetivo utilizar membranas confeccionados pela MA como suportes para imobilização de proteínas, que poderão ser utilizadas em estudos futuros como uma via para construção rápida e custo-efetiva de biochips customizados.

\section{MATERIAIS E MÉTODOS}

\subsection{Materiais}

A proteína utilizada foi a GH43 $\beta$-xilosidase de Bacillus subtilis, obtida a partir de cultivos de Escherichia coli recombinante e purificada no Laboratório de Engenharia de Processos Enzimáticos do DEQ-UFSCar. As membranas de poliamida foram obtidas por 


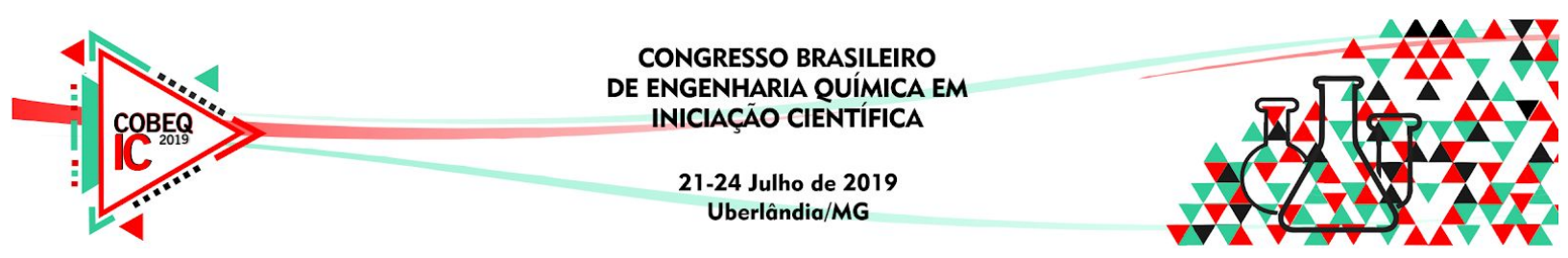

manufatura aditiva (MA) na divisão de Tecnologias Tridimensionais do Centro de Tecnologia da Informação Renato Archer.

Para modificação da química de superfície das membranas foi utilizado glutaraldeído 25\% (solução em água) da ACROS. (3-aminopropil) trietoxisilano (APTES) e 4-Nitrophenyl $\beta$-D-xylopyranoside (PNPX) foram adquiridos da Sigma-Aldrich. Foram utilizados também banho ultratermostático SL152 da Solab e espectrofotômetro SPECORD S6000 da Analytik Jena.

\subsection{MÉTODOS}

\subsubsection{Ativação da Membrana diretamente com Glutaraldeído}

As membranas de poliamida foram cortadas em pedaços medindo aproximadamente $1 \times 0,5 \mathrm{~cm}$ e todos os testes realizados foram realizados em triplicatas. Os pedaços cortados foram colocados em eppendorfs e pesados. Em uma das condições a ativação com glutaraldeído foi realizada adicionando nestes eppendorfs $1,9 \mathrm{~mL}$ de tampão fosfato $\mathrm{pH} 7.0$ $100 \mathrm{mM}$ e $100 \mathrm{uL}$ de glutaraldeído 2,5\% (obtendo uma diluição final do glutaraldeído de 0,125\%). Na outra condição, foi adicionado glutaraldeído 25\% (concentração final de 1,25\%). A solução de $2,5 \%$ de glutaraldeído mencionada foi preparada diluindo $100 \mathrm{uL}$ de glutaraldeído $25 \%$ em $1 \mathrm{~mL}$ de tampão fosfato $\mathrm{pH} 7100 \mathrm{mM}$. Os eppendorfs foram mantidos sob agitação por aproximadamente 16 horas. Após a ativação a membrana foi retirada da solução de glutaraldeído e lavada com água de forma abundante.

Também foram feitos testes onde um pré-tratando da membrana com $\mathrm{HCl} 3 \mathrm{M}$ foi efetuado. Assim, antes da ativação com glutaraldeído, deixou-se a membrana em contato com $\mathrm{HCl}$ por 16 horas. Após esse período o procedimento foi o mesmo descrito anteriormente

\subsubsection{Tratamento da Membrana com APTES}

Em outros experimentos a membrana foi previamente ativada com o reagente APTES antes da ativação com glutaraldeído. Para isso, adicionou-se em cada eppendorf contendo a mambrana $1,750 \mathrm{~mL}$ de etanol e $75 \mathrm{uL}$ do reagente APTES em 3 porções de $25 \mathrm{uL}$ a cada 24h. Após a ativação com APTES a membrana foi removida da solução de etanol e APTES e ativada com glutaraldeído, conforme apresentado anteriormente. Alguns testes adicionais realizados utilizaram $300 \mathrm{uL}$ de APTES, neste caso as porções adicionadas a cada $24 \mathrm{~h}$ foram de $100 \mathrm{uL}$.

\subsubsection{Medida de Atividade Enzimática}

Para as medidas de atividade enzimática da $\beta$-xilosidase (BetaXi) foi utilizado o substrato sintético pnpx $5 \mathrm{mM}$ preparado em tampão fosfato $50 \mathrm{mM} \mathrm{pH} \mathrm{6.0.} \mathrm{Em} \mathrm{um}$ eppendorf, levou-se $1 \mathrm{~mL}$ do preparado de substrato a um banho termostático em $35^{\circ} \mathrm{C}$ por aproximadamente 2 minutos, para que este atingisse a temperatura do meio. Adicionou-se ao substrato a membrana de poliamida com a enzima imobilizada, deixando a reação ocorrer por 


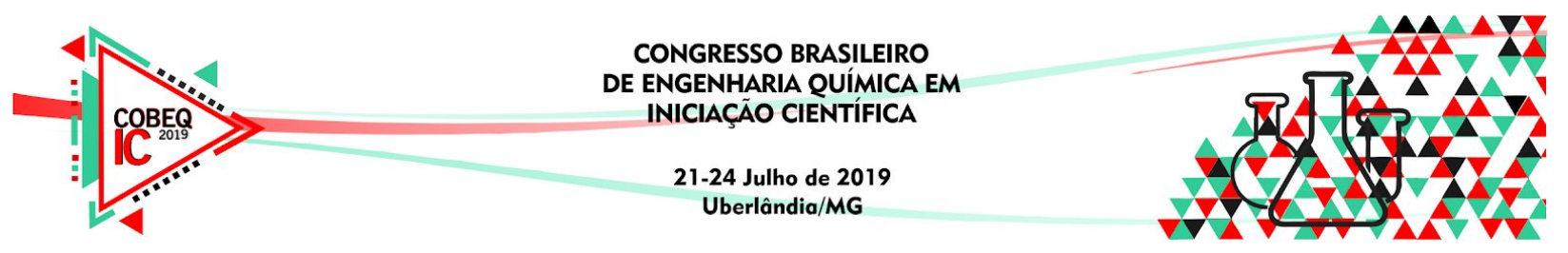

4 a 10 minutos (a depender do andamento da hidrólise, notado visualmente pela coloração amarelada do substrato). Ao final da reação, retirou-se a membrana do eppendorf e levou-se o conteúdo restante do frasco para análise de absorbância no espectro a $410 \mathrm{~nm}$.

Com os valores de absorbância obtidos, calculou-se a atividade enzimática conforme a equação 1 .

$$
\text { atividade }=\frac{\frac{\text { absorrância }}{\text { tempo de reação }} \times \text { Volume de Reação }}{1,95 \times \text { Massa da membrana seca }}
$$

Onde o valor 1,95 corresponde ao coeficiente de absortividade molar do pnpx.

\section{RESULTADOS E DISCUSSÕES}

Buscando verificar qual a melhor condição de imobilização utilizando como suporte a membrana impressa, foram realizados diversos testes de ativação do material em diferentes condições (figura 1). As análises espectrofotométricas permitiram distinguir quais testes apresentaram melhores resultados por meio do cálculo da atividade enzimática conforme apresentado na Figura 1.

Figura 1 - Atividade obtida para imobilização de BetaXi em membrana em diversas condições de tratamento e ativação.

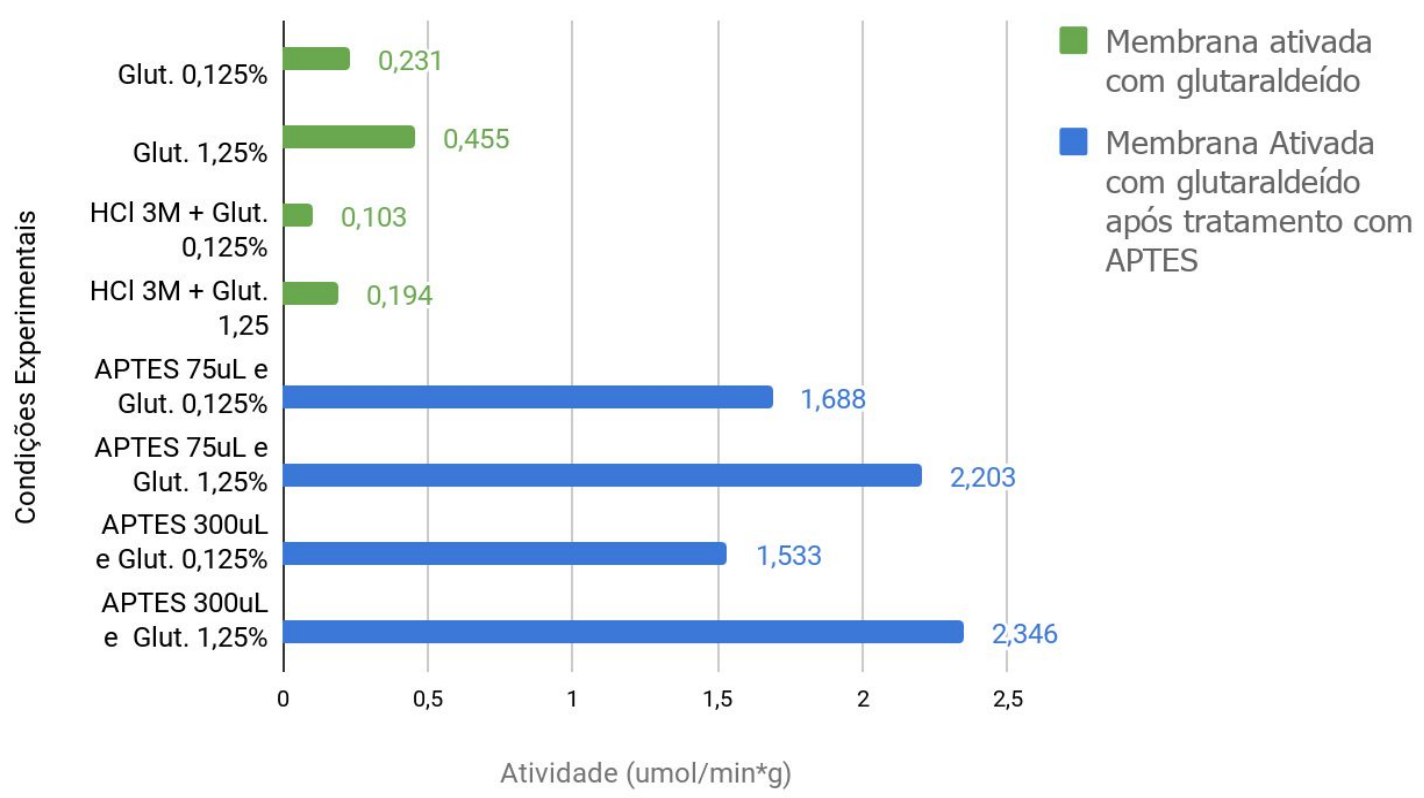

\subsection{Efeito da Adição de Glutaraldeído na Ativação da Membrana}

Os testes iniciais foram realizados sem a adição do aminosilano, a fim de verificar se a imobilização poderia ser efetiva apenas com ativação das membranas com glutaraldeído (figura 1), como descrito em outros trabalhos (WONG, 2017). Conforme observado, o valor 


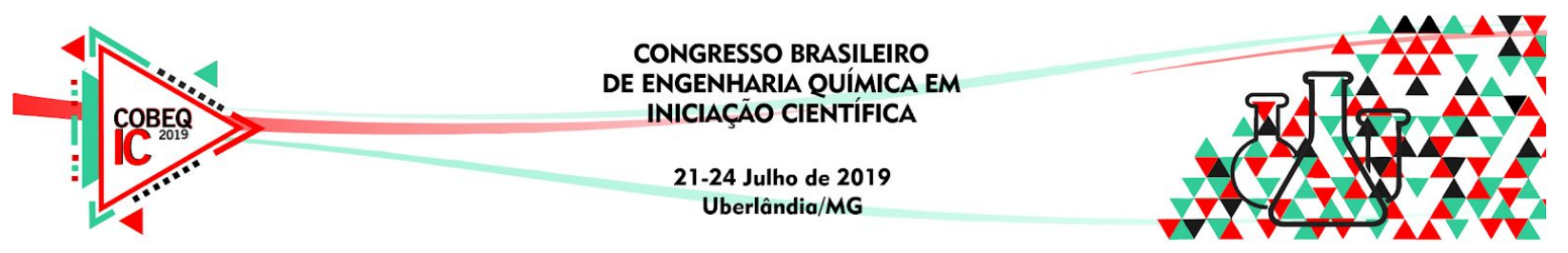

obtido de atividade foi bem baixo, indicando assim que somente a ativação da membrana com glutaraldeído seria insuficiente para um bom desempenho de imobilização. Desta forma, testes adicionais foram realizados utilizando $\mathrm{HCl} 3 \mathrm{M}$ previamente à ativação com glutaraldeído, a fim de verificar se esta etapa poderia ocasionar melhorias, mas o processo continuou a apresentar resultados insatisfatórios. Vale ressaltar que a ineficiência da imobilização também pode ser observada visualmente, já que não notou-se mudança de coloração do substrato proveniente de uma possível hidrólise do substrato sintético durante a reação, o que gera uma coloração amarelada.

\subsection{Efeito do Pré-tratamento das Membranas com APTES}

Prosseguiu-se para os testes com adição do aminosilano APTES anteriormente a ativação com Glutaraldeído (figura 1). Nesta etapa foi verificado que houve imobilização significativa da enzima na superfície do material, fato que também pôde ser observado visualmente devido a com a coloração amarelada presente tanto na membrana (figura 2) quanto no substrato após a reação.

Figura 2 - Membrana pré tratada com APTES (75uL) e Glutaraldeído (1,25\%), após o procedimento de imobilização de $\beta$-xilosidase purificada e reação com PNPX.

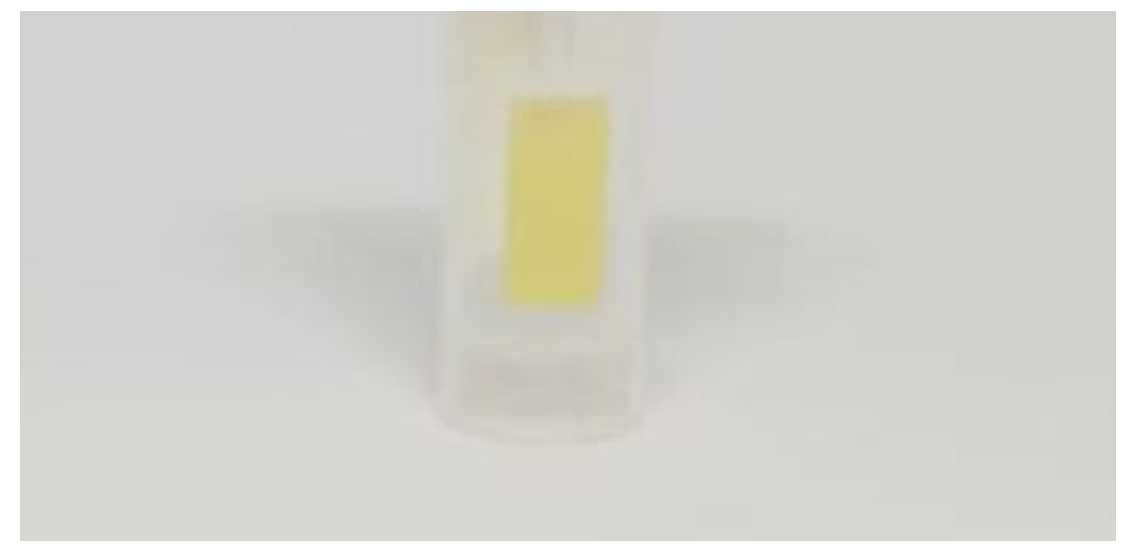

Através da figura 1, é possível observar ainda que o aumento na concentração de glutaraldeído resultou em maiores valores de atividade da membrana que está diretamente relacionado com a concentração de enzimas cataliticamente ativas imobilizadas na superfície do material. Já o aumento da concentração de APTES no pré-tratamento não surtiu grandes efeitos na atividade final da membrana. Assim, a melhor condição obtida foi aquela realizada com 75 uL de APTES no pré-tratamento e 1,25\% de glutaraldeído na ativação, onde a atividade obtida foi de $2,203 \mu \mathrm{mol} * \mathrm{~min} / \mathrm{g}$.

\section{CONCLUSÃO}

A ativação da membrana somente com glutaraldeído resultou em um suporte ineficaz para a imobilização da proteína, diferentemente de quando realizou-se um pré-tratamento com APTES onde a imobilização ocorreu em diversas condições. O uso de altas concentrações de 


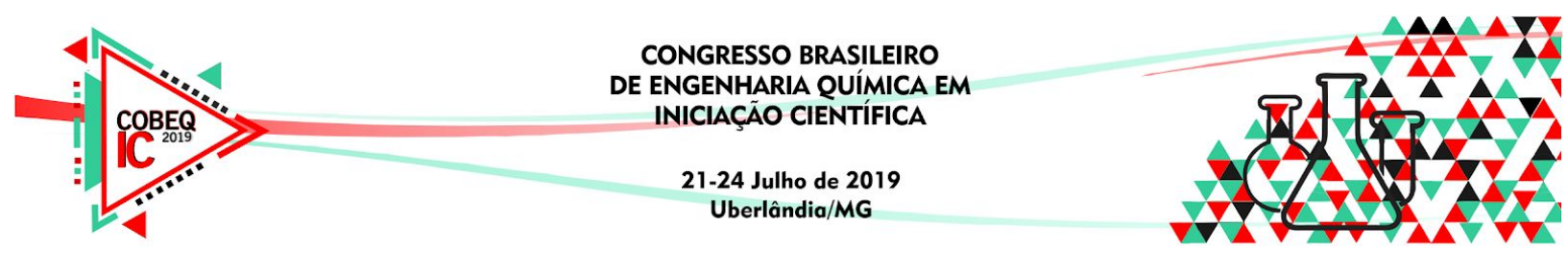

APTES no pré tratamento das membranas não resultou em melhores resultados em comparação com os testes em que se utilizou menores concentrações deste reagente. Com isso, a melhor condição obtida foi aquela realizada com $75 \mathrm{uL}$ de APTES no pré-tratamento e $1,25 \%$ de glutaraldeído na ativação (figura 1 e 2).

\section{REFERÊNCIAS}

BECARO, A. A. Imobilização e estabilização de D-Hidantoinase para produção de N-Carbamoil-D-fenilglicina. Dissertação de mestrado, Universidade Federal de São Carlos, Setembro de 2008.

CARVALHO, N. B.; LIMA, A.S; SOARES, C. M. F. Uso de sílicas modificadas para imobilização de lipases. Quim. Nova, v. 38, p. 399-409, 2015.

LI, C. M.; DONG, H.; ZHOU, Q.; GOH, K. H. Electrochemical sensors, biosensors and their biomedical applications . Academic Press, p. 308-383, 2008.

SOUZA, E. A.; ROCHA, L. A; FARIA, E. H.; CIUFFI, K. J.; NASSAR, E. J.; SILVA, J. V. L.; OLIVEIRA, M. F.; MAIA, I. A. Incorporation of the chemotherapy medication cisplatin into polyamide membrane. Journal of Inorganic Biochemistry, v. 180, p. 171-178, 2018.

SOUZA, E. A.; CAMPONESA, B. M; ROCHA, L. A.; FARIA, E. H.; CIUFFA, K. J.; NASSAR, E. J.; SILVA, J. V. L.; OLIVEIRA, M. F.; MAIA, I. A. Modificação de membrana de poliamida via sol-gel e incorporação de composto de európio (III) luminescente. Quim. Nova, v. 39, p. 1044-1050, 2016.

SOUZA, M. L.; MOSCARDINIA, S. B; FARIA, E. H.; CIUFFI, K. J.; ROCHA, L. A.; NASSAR, E. J.; SILVA, J. V. L.; OLIVEIRA, M. F.; MAIA, I. A. Óxido de ítrio e alumínio dopado com $\mathrm{Yb}^{3+}$ e $\mathrm{Er}^{3+}$ incorporado em membrana de poliamida. Quim. Nova, v. 41, p. 519-527, 2018.

WONG, D. E.; SENECAL K. J.; GODDARD, J. M. Immobilization of chymotrypsin on hierarchical nylon 6,6 nanofiber improves enzyme performance. Colloids and Surfaces B:Biointerfaces, v. 154, p. 270-278, 2017. 